\title{
Cardiovascular drug therapy and surrogate COVID-19 outcomes: which is the impact of the "miraculous" sodium- -glucose co-transporter-2 inhibitors?
}

\author{
Dimitrios Patoulias', Christodoulos Papadopoulos², George Kassimis ${ }^{3}$, Michael Doumas ${ }^{1,4}$ \\ $1^{2} 2^{\text {nd }}$ Propedeutic Department of Internal Medicine, Aristotle University of Thessaloniki, General Hospital "Hippokration", Thessaloniki, Greece \\ ${ }^{2} 3^{\text {rd }}$ Department of Cardiology, Aristotle University of Thessaloniki, General Hospital "Hippokration”, Thessaloniki, Greece \\ ${ }^{3} 2^{\text {nd }}$ Department of Cardiology, Aristotle University of Thessaloniki, General Hospital "Hippokration", Thessaloniki, Greece \\ ${ }^{4}$ Veterans Affairs Medical Center, George Washington University, Washington, District of Columbia, United States
}

\author{
Correspondence to: \\ Dimitrios Patoulias, MD, \\ $\mathrm{MSc}, \mathrm{PhD}(\mathrm{c})$, \\ $2^{\text {nd }}$ Propedeutic \\ Department of Internal \\ Medicine, \\ General Hospital \\ "Hippokration", \\ Konstantinoupoleos 49, \\ 54642, Thessaloniki, Greece, \\ phone: +30 69469007 77, \\ e-mail: \\ dipatoulias@gmail.com \\ Copyright by the Author(s), \\ 2021 \\ Kardiol Pol. 2021; \\ 79 (9): 1048-1049; \\ DOI: 10.33963/KP.a2021.0067 \\ Received: \\ June 26, 2021 \\ Revision accepted: \\ July 2, 2021 \\ Published online: \\ July 16, 2021
}

\section{TO THE EDITOR}

We really appreciated the results of the observational study conducted by Terlecki et al. [1], who demonstrated that, in a total of 1729 patients admitted to hospital due to coronavirus disease 2019 (COVID-19), history of diabetes mellitus significantly increased the odds of in-hospital death by $53 \%$, while those patients with concomitant heart failure (HF) experienced a two-fold increase in the corresponding odds. Researchers have also shown in their cohort that prior treatment with renin-angiotensin-aldosterone system blockers, statins, antiplatelet drugs, or beta-blockers was associated with a significant decrease in the odds of in-hospital death, confirming a protective role of these drug classes against the most surrogate COVID-19 outcome [1].

Recently, there has been a vivid and ongoing discussion concerning the place of sodium-glucose co-transporter-2 (SGLT-2) inhibitors in the therapeutic management of patients with COVID-19 [2]. This drug class has an established role in the treatment of type 2 diabetes mellitus, while it has gained significant ground in the treatment armamentarium against $\mathrm{HF}$, especially in patients with $\mathrm{HF}$ with reduced ejection fraction (HFrEF), even without concomitant type 2 diabetes mellitus [3].

According to a recently published nationwide cohort study from the National Diabetes Audit in England, prescription of SGLT-2 inhibitors is associated with a significant decrease in the risk for COVID-19 related death by $18 \%$ [4]. However, relevant data remain scarce and conflicting, as far as pathophysiologic background is concerned, and thus, further research on this field is required [5].

Therefore, it would be very interesting and would increase a value of the initial report, if Terlecki et al. [1] could provide data concerning the usage rates of SGLT- 2 inhibitors in their cohort and the association with crude outcomes, such as mechanical ventilation and in-hospital death, since this "miraculous" drug class has attracted scientific interest, with an established role in the secondary prevention of cardiovascular disease. Data from such real-world studies may influence decision-making and improve therapeutic strategy if we confront another COVID-19 pandemic wave in the near future.

\section{Article information \\ Conflict of interest: None declared.}

Open access: This article is available in open access under Creative Common Attribution-Non-Commercial-No Derivatives 4.0 International (CC BY-NC-ND 4.0) license, allowing to download articles and share them with others as long as they credit the authors and the publisher, but without permission to change them in any way or use them commercially. For commercial use, please contact the journal office at kardiologiapolska@ptkardio.pl.

How to cite: Patoulias D, Papadopoulos C, Kassimis G, Doumas M. Cardiovascular drug therapy and surrogate COVID-19 outcomes: which is the impact of the "miraculous" sodium-glucose co-transporter-2 inhibitors? Kardiol Pol. 2021; 79(9): 1048-1049, doi: 10.33963/KP.a2021.0067. 


\section{REFERENCES}

1. Terlecki M, Wojciechowska W, Klocek M, et al. Association between cardiovascular disease, cardiovascular drug therapy, and in-hospital outcomes in patients with COVID-19: data from a large single-center registry in Poland. Kardiol Pol. 2021; 79(7-8): 773-780, doi: 10.33963/KP.15990, indexed in Pubmed: 33926173.

2. Scheen AJ.SGLT2 inhibition during the COVID-19 epidemic: Friend or foe? Diabetes Metab. 2020;46(5): 343-344, doi: 10.1016/j.diabet.2020.06.003, indexed in Pubmed: 32562762.

3. Nessler J, Siniarski A, Leszek $P$, et al. Expert opinion of the Heart Failure Working Group of the Polish Cardiac Society on the use of dapagliflozin in the treatment of heart failure with reduced ejection fraction. Kardiol
Pol. 2021; 79(3): 363-370, doi: 10.33963/KP.15859, indexed in Pubmed: 33687868.

4. Khunti K, Knighton P, Zaccardi F, et al. Prescription of glucose-lowering therapies and risk of COVID-19 mortality in people with type 2 diabetes: a nationwide observational study in England. Lancet Diabetes Endocrinol. 2021; 9(5): 293-303, doi: 10.1016/S2213-8587(21)00050-4, indexed in Pubmed: 33798464

5. Patoulias D, Papadopoulos C, Katsimardou A, et al. Sodium-glucose cotransporter 2 inhibitors and major COVID-19 outcomes: promising mechanisms, conflicting data, and intriguing clinical decisions. Diabetes Ther. 2020; 11(12):3003-3005, doi: 10.1007/s13300-020-00942-7, indexed in Pubmed: 33052538. 